\title{
CUSTOS DE FORMALIZAÇÃO INSTITUCIONAL DE SISTEMAS AGROINDUSTRIAIS FAMILIARES DE BASE ECOLÓGICA - SAFES1
}

\section{COSTS SYSTEMS INSTITUTIONAL FORMALIZATION AGROINDUSTRIAL BASE OF FAMILY ECOLOGICAL - SAFES}

\author{
Marcio Gazolla \\ Universidade Tecnológica Federal do Paraná - Pato Branco - PR - Brasil
}

Arlindo Jesus Prestes de Lima

Universidade Federal de Santa Maria - Santa Maria - RS - Brasil

Carolina Brignoni

Universidade Federal de Santa Maria - Santa Maria - RS - Brasil

Andressa Bammesberger

Universidade Federal de Santa Maria - Santa Maria - RS - Brasil

\begin{abstract}
Resumo: O objetivo do trabalho foi mensurar quanto e quais são os custos de produção de sistemas agroindustriais familiares que possuem a agricultura ecológica como base de reprodução social. Neste sentido, foram relacionados, sempre comparativamente, indicadores de desempenho econômico das situações de formalidade e informalidade institucional das experiências investigadas. As perguntas que guiaram a pesquisa foram: quanto e quais são os custos para viabilizar um sistema agroindustrial ecológico nas situações de formalidade e informalidade institucional? Haveria diferenças monetárias significativas? Dentro disso, qual seria o custo da certificação orgânica? A pesquisa foi desenvolvida na Regional da EMATER de Frederico Westphalen/RS, onde foram investigadas doze iniciativas, utilizando-se do

1 O presente trabalho é fruto de um projeto de pesquisa ligado ao Edital MCTI/MAPA/MDA/MEC/MPA/CNPq N 81/2013, chamado de "Proposta de criação de um Núcleo de Estudo em Agroecologia e Produção Orgânica (NEA)". O mesmo é coordenado pela UFRGS, com participação da UFSM, FURG e EMATER e foi financiado através de recursos dos Ministérios acima listados, operacionalizados pelo CNPq (2014-15).
\end{abstract}


aporte teórico-metodológico de avaliação econômica dos sistemas de produção. De maneira geral, os resultados evidenciam que os sistemas agroindustriais familiares ecológicos possuem menores custos de produção em situação de informalidade por um lado e, de outro, que seu valor agregado e renda agroindustrial também se elevam quando estes não seguem as legislações agroalimentares emanadas do Estado, em diferentes níveis territoriais.

Palavras-chave: Custos de formalização institucional. Sistema agroindustrial familiar. Cadeias produtivas ecológicas.

Abastract: The objective was to measure how much and what are the production costs of family agroindustrial systems that have ecological agriculture as the basis of social reproduction. In this sense, they were related, always comparatively economic performance indicators of formality situations and institutional informality of the investigated experiences. The questions that guided the research were: how much and what are the costs to enable an ecological agroindustrial system in situations of formality and informality institutional? There would be significant monetary differences? Within that, what would be the cost of organic certification? The research was conducted in the Regional EMATER of Frederico Westphalen/RS, which were investigated twelve initiatives, using the theoretical and methodological support of economic evaluation of production systems. Overall, the results show that the ecological family agroindustrial systems have lower production costs in informal situations on the one hand and, on the other, that your household and agroindustrial income value also increase when they do not follow the agrifood legislation issued by the State in different territorial levels.

Keywords: Costs of institutional formalization. Family agroindustrial system. Ecological production chains.

\section{Introdução}

Os alimentos provenientes da agricultura de base ecológica estão sendo vistos como uma alternativa dentro do sistema agroalimentar, especialmente por portarem valores em torno da sustentabilidade ambiental, bem estar animal, saúde humana e preocuparem-se com princípios éticos e de justiça social (RODRIGUES, 2012; SAGE, 2013). Segundo Niederle e Raulet (2014) a agricultura orgânica tem se revelado um dos segmentos agroalimentares com maior expansão mundial, sendo que em 2012, movimentou 750 milhões de reais, com expectativas de ampliação para 1 bilhão de reais em 2014.

Muito deste crescimento tem sido pelo lado da demanda. São os consumidores críticos e reflexivos que assuem a protuberância de exigir dos mercados alimentos em formatos mais sustentáveis (GIDDENS; 
BECK; LASH, 1997). Por exemplo, na Alemanha, que possui em torno de 80 milhões de consumidores, o espaço para os produtos orgânicos situa-se entre $10 \%$ e $15 \%$ do total de alimentos consumidos no país. Estimativas do Ministério da Agricultura, Pecuária e Abastecimento (MAPA) preveem um aumento de $20 \%$ do consumo de orgânicos no país, algo em torno de 2,5 milhões de reais em 2016.

No Brasil os dados do Censo Agropecuário (IBGE, 2006) evidenciam que 90.498 estabelecimentos agropecuários fazem este tipo de produção, representando $1,75 \%$ do total de estabelecimentos existentes. Deste total, apenas 5.106 estabelecimentos são certificados, representando percentualmente 5,64\%. Na Região Sul do país os dados do Censo mostram que em torno de 19.276 estabelecimentos praticam a agricultura orgânica, o que representa 1,92\% sobre o total dos estabelecimentos existentes. Destes quase 20 mil estabelecimentos, 1.924 são credenciados por entidades que certificam a produção, sendo a Região Sul, entre as cinco do país, a que mais certificação orgânica possui (IBGE, 2006).

Uma das questões levantadas por estudiosos das experiências que produzem alimentos diferenciados, por exemplo, produtos da agricultura de base ecológica associados à transformação agroalimentar é a grande dificuldade encontrada pelos atores sociais para cumprir todos os regramentos institucionais perante as agências de regulação do Estado, em diferentes níveis federativos (MIOR, 2005; WILKINSON; 2008). A chamada formalização institucional destas propriedades ecológicas associadas com agroindústrias compreende o cumprimento da legislação agroalimentar de produção, comercialização e consumo dos alimentos e produtos, tendo que adequar-se a normativas em várias dimensões (aspectos sanitários, fiscais, jurídicos, ambientais, certificação, entre outros), dependendo do tipo de produto e de registro do estabelecimento.

Alguns estudos nesta área têm colocado como entrave ao processo de formalização institucional o alto custo financeiro a ser arcado pelos sistemas produtivos dos agricultores familiares (RAUPP, 2009; WESZ JÚNIOR, 2009; GAZOLLA, 2014). Contudo, não se dispõe de estudos sobre o tema, que diagnosticaram e aferiram quais e quanto são estes custos para estes sistemas produtivos? Dizendo de outra forma: quanto e quais são os desembolsos para viabilizar um sistema 
produtivo ecológico nas situações de formalidade e informalidade institucional? Haveria diferenças monetárias significativas? Dentro disso, qual seria o custo da certificação orgânica?

É neste sentido que o artigo tenta contribuir. Seu objetivo é mensurar quanto e quais são os custos de produção de sistemas produtivos familiares que possuem a agricultura ecológica como base de reprodução social. Neste sentido, se levantou a rentabilidade em termos de valor agregado e renda agroindustrial de cada sistema, bem como de suas principais cadeias produtivas. Também foram relacionados, sempre comparativamente, indicadores de desempenho econômico das situações de formalidade e informalidade institucional das experiências investigadas.

Denomina-se de Sistemas Agroindustriais Familiares de Base Ecológica (SAFE) as experiências investigadas devido a três motivos. Primeiro por dar uma ideia de análise sistêmica e integrada dos sistemas de produção das propriedades. Segundo, devido ao fato de pesquisarem-se formas sociais familiares de produção e trabalho nos espaços rurais, onde a administração e decisões são estrategicamente tomadas pelo grupo doméstico, de forma proativa. Terceiro, pela análise conduzida elucidar a dinâmica ecológica e econômica de produção tanto de aspectos ligados as matérias primas como dos alimentos transformados pelas famílias.

O trabalho foi desenvolvido no Norte do Rio Grande do Sul, seguindo a espacialização do Escritório Regional da EMATER de Frederico Westphalen, que abrange 42 municípios gaúchos. Foram investigados doze sistemas produtivos de base ecológica, utilizando-se essencialmente de dados provenientes de um roteiro de questões aplicado junto aos agricultores, no ano de 2014, embora, utilizam-se algumas informações pontuais de preços, indicadores técnicos e produtivos e valores econômicos de fontes secundárias e de outros atores sociais.

O trabalho está separado em cinco seções, além da introdução e das considerações finais. Na primeira apresenta-se a metodologia do trabalho e dos cálculos econômicos. Na segunda a noção de SAFE e dos custos de formalização institucional. $\mathrm{Na}$ terceira caracteriza-se, brevemente, as experiências pesquisadas. E, nas últimas partes apresentam-se os resultados da investigação de forma comparativa 
entre as situações de formalidade e informalidade, bem como se desenvolve algumas comparações de indicadores de desempenho econômico entre cadeias produtivas (por área e per capita).

\section{Metodologia de pesquisa e cálculo dos indicadores produtivos e econômicos}

A metodologia de pesquisa possuiu várias etapas. Primeiro, elaborou-se o roteiro de pesquisa semiestruturado o qual continha as principais questões a avaliação econômica dos sistemas produtivos, dividindo as perguntas segundo os dois subsistemas a analisar: produção primária e agroindustrial. A segunda etapa consistiu na identificação das experiências e serem investigadas. A amostra foi dirigida e intencional já que se procurava iniciativas que estivessem em processo de transição ecológica ou já consolidadas na produção orgânica.

Para isso, contou-se com a ajuda do Escritório Regional da EMATER de Frederico Westphalen/RS, que indicou possíveis iniciativas com as características requeridas, nos 42 municípios de sua abrangência. Foram identificadas quinze experiências potenciais de serem entrevistadas, contudo, três declinaram da entrevista. Restaram doze iniciativas que foram investigadas, conforme são apresentados na seção de caracterização das mesmas.

A metodologia de avaliação econômica das experiências seguiu o roteiro de cálculos para avaliação de sistemas de produção, propostos por Lima et al (1995) com pequenas inserções dos conceitos trabalhados por Hoffmann et al (1989). No Box 1 é possível visualizar a sequência lógica de cálculos desenvolvidos na pesquisa. Primeiro foi calculado o Valor Agregado (VA), através da subtração do Consumo Intermediário (Cl) e das Depreciações (D) do Produto Bruto (PB). O segundo passo foi calcular o Valor Agregado Bruto (VAB), descontandose do $\mathrm{PB}$ o valor do $\mathrm{Cl}$. Também, calculou-se o Valor Agregado Líquido (VAL), descontando-se do VAB os valores das depreciações (D).

Box 1. Sequência de passos para cálculos dos indicadores econômicos

\begin{tabular}{|c|}
\hline $\mathrm{VA}=\mathrm{PB}-\mathrm{Cl}-\mathrm{D}$ \\
\hline $\mathrm{VAB}=\mathrm{PB}-\mathrm{Cl}$ \\
\hline $\mathrm{VAL}=\mathrm{VAB}-\mathrm{D}$ \\
\hline
\end{tabular}




\begin{tabular}{c|}
\hline $\mathrm{RAI}=\mathrm{VA}-\mathrm{DVA}$ \\
\hline $\mathrm{RAI}=\mathrm{PB}-\mathrm{CTP}$, onde CTP $=\mathrm{CF}+\mathrm{CV}$ \\
\hline
\end{tabular}

Fonte: Adaptado de Lima et al (1995) e Hoffmann et al (1989).

$\mathrm{Na}$ terceira etapa de cálculos, obteve-se a Renda Agroindustrial (RAl), da dedução dos valores do VA da Divisão do Valor Agregado (DVA). A RAl também pode ser obtida pela metodologia dos custos (fixos e variáveis), como é descrito por Hoffman et al (1989). Neste caso, se deduz da PB os Custos Totais de Produção (CTP), que é a soma dos Custos Fixos (CF), mais os Custos Variáveis (CV) ${ }^{2}$. Em todos os dados e cálculos desenvolvidos utilizou-se informações anuais, tendo por base o ano de 2014. Estes conceitos mencionados acima, são mais bem compreendidos a partir do Box 2, que os define precisamente.

Os indicadores econômicos, técnicos e produtivos foram primeiramente calculados em planilhas individuais de cada experiência, utilizando o Software Microsoft Excel. Posteriormente, os principais dados e informações estatísticas de cada uma das doze iniciativas, foram agrupados em um banco agregado, no qual se fez as análises referentes à estatística descritiva e outras análises que estão apresentadas nas seções de resultados.

Para obtenção do valor do custo de formalização das iniciativas, que é o objetivo deste trabalho, os cálculos econômicos foram desenvolvidos de duas maneiras diferentes. Numa primeira etapa, considerando as agroindústrias formalizadas perante os regramentos do Estado, desde os aspectos sanitários, ambientais, fiscais, trabalhistas, certificação orgânica, entre outros. Num segundo momento, considerando-as informais perante estas exigências institucionais. A diferença entre estas duas situações é demonstrada, tanto no caso dos custos de produção, como nos indicadores de desempenho econômico calculados.

Box 2. Principais conceitos de custos e indicadores econômicos de desempenho

Depreciação (D): A depreciação é um custo produtivo que os agricultores possuem com o desgaste de sua infraestrutura produtiva, especificamente seus capitais fixos, que tendem a perder valor pelo uso, tempo de vida e obsolescência tecnológica.

2 Para um maior aprofundamento das noções do Box 2, consultar Hoffmann et al (1989) e Lima et al (1995). 
Consumo Intermediário ( $\mathrm{Cl}$ ): São todos os custos com insumos e serviços que adentram o processo de produção das propriedades rurais, excetuando-se os custos com a força de trabalho. São bons exemplos de desembolsos com consumo intermediário a aquisição de sementes, corretivos do solo, rações, entre outros.

Divisão do Valor Agregado (DVA): É definido como todos os custos associados ao pagamento de serviços, empréstimos, arrendamentos, juros, impostos e força de trabalho contratada na unidade de produção. Possui este nome, por que na prática, o agricultor divide sua riqueza com os demais agentes econômicos e produtivos da sociedade e do Estado.

Custos Variáveis (CV): São os custos que variam com a quantidade de produção das propriedades rurais; são os que acompanham o volume de produção da unidade. Além disso, estes custos geralmente são relacionados ao capital consumido em um ciclo produtivo, geralmente safra ou ano agrícola.

Custos Fixos (CF): São aqueles custos que não variam com o volume de produção da unidade, não seguindo as quantidades físicas produzidas. Eles também possuem como característica serem usados para mais de um ciclo de produção das propriedades (safras agrícolas).

Ponto de Nivelamento (PN): É definido como a quantidade da produção bruta necessária para cobrir os custos variáveis de produção da propriedade; dito de outra forma é o valor monetário de produção bruta necessária para pagar os gastos variáveis com o processo produtivo ecológico.

Nível de Reprodução Simples (NRS): É atribuir custo de oportunidade a força de trabalho familiar presente na unidade, de forma que se possa comparar rendimentos auferidos na produção de alimentos e produtos, com os valores que este mesmo trabalhador receberia, por exemplo, em um emprego urbano, recebendo um salário mínimo mensal (incluindo $13^{\circ}$ salário) por unidade de trabalho homem ocupada (UTH).

Produção Bruta (PB): É obtida a partir da multiplicação das quantidades físicas de cada produto com seu respectivo preço. Exceção é a produção para autoconsumo, em que foram usados os dados médios por estabelecimento do RS, com base no Censo Agropecuário do IBGE (2006).

Valor Agregado (VA): É definido como o valor da produção bruta restante, depois de descontados desta as parcelas do consumo intermediário e depreciações. O valor agregado indica o quanto um sistema produtivo consegue gerar de riqueza, a partir da conjugação dos seus fatores de produção (recursos naturais, capital, força de trabalho e tecnologia). Este indicador também pode ser calculado em termos brutos (VAB) e líquidos (VAL).

Renda Agroindustrial (RAI): Representa a parcela do valor agregado que resta, após ser subtraído deste os valores da divisão do valor agregado. Também pode ser conceituado, alternativamente, como o excedente econômico retido, depois de descontado da produção bruta os custos totais de produção (fixos + variáveis) de um sistema produtivo. É a parcela de recursos financeiros sobrantes ao agricultor, geralmente utilizada para reproduzir a família e reinvestir na unidade de produção (ecológica).

Fonte: Adaptado de Lima et al (1995) e Hoffmann et al (1989). 
Neste sentido, os dados usados na comparação foram levantados com os próprios agricultores, quando os mesmos possuíam a informação. Em outros casos, se buscou estes dados com técnicos da área, sites especializados, agricultores há mais tempo na atividade ecológica ou estimou-as com base nas informações disponíveis de outros atores sociais. 


\section{Sistemas Agroindustriais Familiares de Base Ecológica (SAFEs) e custos de formalização institucional}

A noção de sistema é proveniente da Teoria Geral dos Sistemas, segundo a qual há diferentes sistemas interligados (políticos, econômicos, sociais, tecnológicos, produtivos, etc.), dispostos em diferentes níveis da sociedade (ESTEVES DE VASCONCELLOS, 2006). No caso da agricultura e do desenvolvimento rural fala-se em sistemas agrários (MAZOYER; ROUNDART, 2001). Dentro da noção de sistemas agrários, o trabalho enfoca os SAFEs, que são definidos como um tipo específico e misto de sistemas familiares de produção de alimentos, produtos e matérias primas in natura e de transformação agroindustrial de alimentos e produtos agropecuários, possuindo como base os processos ecológicos de produção e processamento agroalimentar.

Neste sentido, o SAFE é formado por dois subcomponentes. O primeiro, o subsistema familiar de produção de matérias primas e alimentos in natura. Este estrutura-se a partir dos elementos tecnológicos, produtivos, força de trabalho familiar e dos meios de produção disponíveis nas unidades. Nele está contida a produção agropecuária e de alimentos que serve de base ao desenvolvimento do subsistema agroindustrial, como já evidenciaram outros estudos (MIOR, 2005; MALUF, 2004; GAZOLLA, 2013).

O segundo, o subsistema agroindustrial é aquele que processa o conjunto de matérias primas produzidas pelo primeiro subsistema, transformando-as em alimentos e produtos elaborados de maior valor agregado para serem comercializados em mercados, especialmente locais e cadeias curtas agroalimentares (RENTING et al, 2003). No subsistema agroindustrial as matérias primas a serem processadas são essencialmente provenientes das próprias unidades familiares, embora, em alguns casos, este se abastece comprando matérias primas de outros fornecedores (LIMA et al, 1995) ${ }^{3}$.

Tanto no primeiro subsistema como no segundo, analisam-se unidades familiares, onde o trabalho e administração das mesmas são realizados pela família de forma conjunta, seguindo a distinção clássica

3 Para entender mais aprofundadamente a ideia de existência de sistemas e subsistemas no caso da administração de unidades familiares na agricultura, ver Lima et al (1995). 
ente os elementos presentes na unidade de produção (sistemas produtivos, tecnologias, meios de produção, posse da terra, entre outros) e grupo doméstico (relações sociais familiares, parentesco, comunitárias, sociabilidade e reciprocidade) (SCHNEIDER, 2003; WANDERLEY, 2009).

Outro aspecto que é comum a estes sistemas produtivos é que estes se desenvolvem a partir de técnicas produtivas e conhecimentos presentes no que autores têm denominado de agricultura de base ecológica (ALTIERI, 2004; GLISSMAN, 2009). Dentro deste enfoque, tanto a produção de matérias primas, produtos agropecuários e alimentos do subsistema in natura, bem como as técnicas e processos de transformação presentes no subsistema agroindustrial seguem os princípios da agricultura de base ecológica. Dessa maneira, os sistemas de produção são menos intensivos em uso de insumos externos, tecnologias, meios de produção e conhecimentos exógenos (PLOEG, 2008).

No caso das experiências investigadas, usa-se denominá-las "em processo de transição ecológica". Isto é para mostrar que as iniciativas estão em um movimento social e técnico que envolve evoluções e mudanças de sistemas produtivos intensivos, que seguiam, em alguns casos, os princípios da modernização da agricultura, em direção a um conjunto de práticas agropecuárias mais sustentáveis do ponto de vista do meio ambiente, saúde, dos processos produtivos agroalimentares e dos mercados que constroem. Na literatura internacional este processo histórico de mudanças sociais e técnicas tem sido chamado de transição agroecológica (ALTIERI, 2004; GLISSMAN, 2009). Denominam-se dessa forma as iniciativas pesquisadas por elas estarem em diferentes "degraus evolutivos" do processo de transição ecológica4.

Um dos principais problemas relatados deste tipo de sistema agroindustrial é a sua informalidade institucional, perante os aspectos sanitários, jurídicos, fiscais, ambientais, trabalhistas, entre outros (MIOR, 2005; WILKINSON, 2008; GAZOLLA, 2013). Um dos argumentos que os estudos têm destacado é o alto custo de formalização dos

\footnotetext{
4 È claro que em alguns casos pesquisados a unidade produtiva sempre foi ecológica, não tendo passado pelo processo modernizador e, assim, não realiza transição agroecológica.
} 
mesmos, como um dos motivos que estrutura a decisão das famílias em manterem-se informais perante os regramentos institucionais do Estado em vários níveis (RAUPP, 2009).

Estudo conduzido por Gazolla (2014), na mesma região de investigação, mostrou que os altos custos de produção destes sistemas são um dos principais motivos da não formalização destas experiências. Estes custos estariam ligados à contratação de profissionais, necessidade de realizar análises de alimentos e água, aquisição de matérias primas e embalagens e a montagem da infraestrutura de processamento da agroindústria (por exemplo, máquinas e equipamentos). Em outros casos, a decisão por manter-se na informalidade é devido à alta carga tributária de alguns impostos, por exemplo, o Imposto sobre Circulação de Mercadorias e Serviços (ICMS) e Imposto sobre Produtos Industrializados (IPI) que incidem em alguns alimentos e produtos.

Segundo o autor, em outras ocasiões, os agricultores deparam-se com um complexo de legislações que eles pouco compreendem e, além disso, que devem adequar-se, para poderem registrar seu estabelecimento, produto ou mesmo vender seus alimentos. Todas essas normas que emanam do Estado oneram economicamente os sistemas produtivos, fazendo com que muitos agricultores optem por não adequarem-se as mesmas. Embora o agricultor não faça um cálculo econômico real do desembolso de recursos necessários para tal feito, o mesmo sempre realiza um "cálculo econômico subjetivo" de suas finanças e, em muitas situações, decide por não legalizar sua experiência (CHAYANOV, 1974).

Para além destes motivos, há outras situações que também levam os agricultores a não formalizarem suas experiências como a necessidade de contratação de força de trabalho de fora das unidades, falta de recursos para capital de giro e/ou medo de contratar dívidas em bancos (WESZ JÚNIOR, 2009), excessos de burocracias, a prática histórica da venda dos produtos pelas cadeias curtas agroalimentares (relações diretas dos agricultores com consumidores), propriedades com casal envelhecido, sem sucessor 5 .

5 Para um escrutínio mais detalhado das diferentes situações e dificuldades enfrentadas pelos agricultores em formalizar suas agroindústrias, consultar Gazolla (2012; 2014). 
Especificamente, no que se refere à certificação orgânica, ela também é tida como limitante a formalização das experiências. Um dos aspectos mencionados pelos estudos no Brasil, especialmente no formato auditado, são os altos custos envolvidos no processo de certificação dos alimentos orgânicos (BRANCHER, 2005). Em alguns, inclusive, há um desestímulo dos processos formais de reconhecimento das qualidades orgânicas dos alimentos, implicando em agricultores que preferem deixar a certificação (SCALCO; SERVI, 2014). Dentre os principais motivos alegados para isso estão: o alto custo da certificação, pouco reconhecimento da sociedade (os agricultores orgânicos recebem críticas de seus vizinhos de comunidade que não são orgânicos), exigências em torno do bem estar animal, infestação dos campos por doenças e pragas (diminuindo seus rendimentos), suporte governamental insuficiente (KOESLING et al, 2012), entre outros.

\section{Breve caracterização das experiências investigadas}

$\mathrm{Na}$ Tabela 1 tem-se o ano de origem, a localização espacial municipal das iniciativas e suas respectivas áreas de terras. Nota-se que uma parte das experiências, possui sua origem nos anos de 1990, possuindo em torno de duas décadas de existência. Outras são do inicio deste século ou próximas ao ano de 2010 , sendo bem mais recentes. A área média das experiências é de 18,07 ha, comprovando que os sistemas produtivos ecológicos são desenvolvidos em pequenas propriedades rurais familiares.

Tabela 1. Ano de origem, localização e área de terras dos SAFEs pesquisados

\begin{tabular}{cccc}
\hline SAFEs & Ano de Origem & Municípios (RS) & Área (Ha) \\
\hline SAFE 1 & 2009 & Frederico Westphalen & 4,7 \\
SAFE 2 & 2010 & Cristal do Sul & 12,5 \\
SAFE 3 & 1987 & Seberi & 13,5 \\
SAFE 4 & 2012 & Iraí & 9,2 \\
SAFE 5 & 2000 & Constantina & 4,0 \\
SAFE 6 & 2012 & Constantina & 10,5 \\
SAFE 7 & 2008 & Erval Seco & 23,6 \\
SAFE 8 & 1998 & Nonoaí & 5,0 \\
SAFE 9 & 2005 & Alpestre & 15,0 \\
\hline
\end{tabular}




\begin{tabular}{cccc}
\hline SAFE 10 & 2011 & Frederico Westphalen & 8,8 \\
SAFE 11 & 1987 & Caiçara & 45,0 \\
SAFE 12 & 1997 & Novo Barreiro & 55,0 \\
\hline Média & & & $\mathbf{1 8 , 0 7}$ \\
\hline
\end{tabular}

Fonte: Pesquisa NEA (Banco de Dados Agregado, 2015).

A Tabela 2 apresenta outros indicadores relacionados à força de trabalho das propriedades rurais e seus diferentes usos (agroindústria, venda dos produtos/alimentos e destinado à produção primária). 0 número total de Unidades de Trabalho Homem (UTHs) é 41, existindo, em média, 3,42 UTHs/SAFE, podendo ser força de trabalho familiar (na maioria dos casos) ou contratada e de sócios. Embora, haja casos em que este número é menor, sendo formado apenas pelo casal (2 UTHs) ou maior, até 4 UTHs, no caso de iniciativas de ação coletiva como é o caso do SAFE $8^{6}$.

Na mesma Tabela é possível observar o total de horas de trabalho anuais nas experiências, que foram de 107.220 horas/ano, sendo em média mobilizadas por cada um dos sistemas de base ecológica 7.935,00 horas anuais de trabalho. Este total de horas trabalhadas foi dividido entre as atividades de agroindustrialização, comércio dos produtos e trabalho na produção das matérias primas. De maneira geral, nota-se uma predominância de horas trabalhadas nas atividades de transformação dos alimentos, ficando, em média, com quase a metade de todo o tempo de trabalho gasto $(46,71 \%)$. Grosso modo, este dado demonstra que nos sistemas ecológicos a principal atividade em termos de ocupação da força de trabalho é a agroindustrialização.

Tabela 2. Força de trabalho e total de horas trabalhadas/anos e sua repartição estre as atividades na agroindústria, comércio e produção

\begin{tabular}{c|c|c|c|c|c}
\multicolumn{6}{c}{ primária } \\
SAFEs & UTHs & $\begin{array}{c}\text { Total de } \\
\text { Horas } \\
(\text { Hs/a) }\end{array}$ & $\begin{array}{c}\text { Agroindústria } \\
(\%)\end{array}$ & $\begin{array}{c}\text { Comércio } \\
(\%)\end{array}$ & $\begin{array}{c}\text { Prod. primária } \\
(\%)\end{array}$ \\
\hline SAFE 1 & 2 & 3.900 & 24,23 & 60,00 & 15,77 \\
SAFE 2 & 3 & 6.600 & 47,27 & 27,27 & 25,45 \\
SAFE 3 & 4 & 9.600 & 45,75 & 12,00 & 42,00 \\
SAFE 4 & 3 & 7.200 & 73,33 & 3,33 & 23,33 \\
SAFE 5 & 4 & 8.400 & 34,29 & 8,57 & 57,14
\end{tabular}

\footnotetext{
6 Uma Unidade de Trabalho Homem (UTH) é igual a um homem adulto, trabalhando 8 horas por dia, durante 300 dias úteis no ano (Hoffman et al, 1989).
} 


\begin{tabular}{cccccc} 
SAFE 6 & 2 & 4.800 & 35,00 & 10,00 & 55,00 \\
SAFE 7 & 2 & 4.800 & 41,25 & 17,50 & 41,25 \\
SAFE 8 & 4 & 9.600 & 40,00 & 20,00 & 40,00 \\
SAFE 9 & 3 & 7.200 & 73,33 & 6,67 & 20,00 \\
SAFE 10 & 4 & 10.320 & 47,91 & 29,65 & 25,35 \\
SAFE 1 1 & 4 & 9.000 & 53,33 & 10,00 & 36,67 \\
SAFE 12 & 6 & 13.800 & 44,78 & 29,13 & 26,09 \\
\hline Média & $\mathbf{3 , 4 2}$ & $\mathbf{7 . 9 3 5}$ & $\mathbf{4 6 , 7 1}$ & $\mathbf{1 9 , 5 1}$ & $\mathbf{3 4 , 0 0}$ \\
\hline
\end{tabular}

Fonte: Pesquisa NEA (Banco de Dados Agregado, 2015).

Já a atividade de comercialização dos alimentos e produtos fica, em média, com 19,51\% do tempo de trabalho disponibilizado pelas famílias. Entre as três atividades classificadas na Tabela 2, esta é a que menos ocupa tempo de trabalho. Isso é devido os mercados e canais de comercialização serem locais e cadeias curtas de abastecimento, com pouco gasto de tempo para fazer as rotas e entregas de produtos, bem como, em muitos casos, os próprios consumidores vem buscar os alimentos ecológicos na propriedade das famílias (GAZOLLA, 2012). As atividades de produção primária ocupam os demais $34 \%$ do tempo de trabalho, ficando em $2^{\circ}$ posto.

No Box 3 estão os principais produtos e alimentos in natura e agroindustrializados dos sistemas de produção investigados. Pode notar a grande diversidade produtiva dos mesmos, em termos de mix de produtos e alimentos existentes. As propriedades produzem desde grãos, frutas, cana de açúcar, cereais de inverno, produtos de horta, erva mate e seus respectivos derivados vegetais (quando existem), bem como animais em geral como frangos, peixes, porcos, gado, abelhas e seus respectivos derivados e produtos obtidos a partir destes como mel, leite, carne e ovos, só para citar alguns.

Box 3. Principais produtos in natura e agroindustrializados dos SAFEs.

\begin{tabular}{|c|c|c|}
\hline SAFEs & Subsistema In Natura & Subsistema Agroindustrial \\
\hline SAFE 1 & $\begin{array}{c}\text { Lixia, framboesa, banana, acerola, } \\
\text { carambola, limão, jabuticaba, fruta } \\
\text { do conde, ovos, galinha, feijão, } \\
\text { caldo de cana, peixe, vinagre e } \\
\text { vinho }\end{array}$ & Mel. \\
\hline SAFE 2 & Gado de corte & Farelo, farinha e canjica \\
\hline SAFE 3 & Milho, porcos, leitões, bovinos & Erva mate ecológica de barbaquá \\
\hline
\end{tabular}




\begin{tabular}{|c|c|c|}
\hline & engorda, queijo e leite. & \\
\hline SAFE 4 & Leite, fumo e milho consumo. & Melado, açúcar, cachaça e etanol. \\
\hline SAFE 5 & Cana de açúcar & $\begin{array}{l}\text { Açúcar, melado batido, melado fino, } \\
\text { bolinhas de açúcar e cachaça. }\end{array}$ \\
\hline SAFE 6 & $\begin{array}{l}\text { Galinha, repolho, alface, leite e } \\
\text { mandioca, ovos, abacaxi. }\end{array}$ & $\begin{array}{l}\text { Conservas (milho, pepino, cebolinha, } \\
\text { vagem preta, pikles misto, uva, } \\
\text { cenoura, beterraba, chuchu, } \\
\text { rabanete, couve flor, brócolis, vagem } \\
\text { branca e pêssego), doces de frutas } \\
\text { (geleia de pera, compota de pera, } \\
\text { geleia de pêssego), molho de rúcula, } \\
\text { waffles, tortelli, salame de chocolate, } \\
\text { lasanha, vinho, queijo. }\end{array}$ \\
\hline SAFE 7 & $\begin{array}{c}\text { Galinha, gado, queijo, porco, caqui, } \\
\text { laranja, pêssego, eucalipto, uva e } \\
\text { ovos. }\end{array}$ & Vinho e suco de uva. \\
\hline SAFE 8 & & Mel envasado e a granel. \\
\hline SAFE 9 & $\begin{array}{l}\text { Vaca, terneiro, novilha, galinha, } \\
\text { ovos, leite, fumo e laranja orgânica. }\end{array}$ & $\begin{array}{c}\text { Melado, açúcar mascavo, doces de } \\
\text { fruta (laranja, goiaba e abóbora), } \\
\text { cachaça litro. }\end{array}$ \\
\hline SAFE 10 & $\begin{array}{l}\text { Milho, soja, feijão, pepino, alface, } \\
\text { pimentão, moranga (cabotiá), } \\
\text { temperos, tomate, queijo, pé de } \\
\text { moleque, porcos e mandioca. }\end{array}$ & Frangos coloniais. \\
\hline SAFE 11 & $\begin{array}{l}\text { Soja, milho, aveia, azevém e cana } \\
\text { de açúcar (venda de mudas). }\end{array}$ & Cachaça e álcool. \\
\hline SAFE 12 & Milho e peixes. & $\begin{array}{c}\text { Erva mate, cuias e bombas de } \\
\text { chimarrão. }\end{array}$ \\
\hline
\end{tabular}

Fonte: Pesquisa NEA (Banco de Dados Agregado, 2015).

No Box 3 também é possível visualizar as principais cadeias produtivas presentes em cada uma das experiências, que serão usadas na comparação de desempenho econômico entre si, nestas próximas seções de resultados do trabalho.

\section{Comparando indicadores econômicos entre as situações formal e informal}


Nesta seção, apresentam-se alguns indicadores de custos de produção e de desempenho econômico das experiências, entre as situações de formalidade e informalidade institucional segundo as normas e regras de produção, comercialização e consumo dos alimentos ecológicos. A ideia básica é comparar as duas situações, especialmente, verificando custos e desempenho econômico que as experiências possuem. Durante a pesquisa, foram avaliadas as situações de formalidade e informalidade institucional nas diferentes dimensões do processo: sanitária, ambiental, tributária, jurídica, fiscal e, inclusive, do ponto de vista da certificação orgânica participativa e/ou auditada. Os resultados são apresentados nesta e na próxima seção do trabalho.

$\mathrm{Na}$ Tabela 3 é possível visualizar a diferença de valores do Custo Total (CT), Custo Fixo (CF) e Variável (CV) das experiências, em relação às situações de formalidade e informalidade (valores formais subtraídos dos informais) ${ }^{7}$. Segundo a Tabela 3 os custos totais médios são quase 20 mil reais menores em situação de informalidade institucional ( $R$ \$ $19.508,94)$, correspondendo em percentuais a algo em torno de $25 \%$ a menos (25,97\%). Este custo total quando aberto em fixo e variável médios, visualiza-se que estes são, respectivamente, $R \$ 13.863,81$ e $R \$$ $5.545,98$ menores em situação informal. Estes dois custos diminuem, percentualmente e respectivamente, em média, $55,44 \%$ e $8,68 \%$ na informalidade institucional.

Tabela 3. Diferenças de custos entre as situações de formalidade e informalidade institucional - Custo Total (CT), Custos Fixo (CF) e Custo

\begin{tabular}{c|c|c|c|c|c|c}
\multicolumn{7}{c}{ Variável (CV) } \\
\hline SAFEs & CT (R\$) & CT (\%) & CF (R\$) & CF (\%) & CV (R\$) & CV (\%) \\
\hline SAFE 1 & $13.815,12$ & 31,17 & $11.663,33$ & 66,70 & $2.151,79$ & 8,02 \\
SAFE 2 & $13.006,67$ & 24,25 & $9.543,33$ & 52,06 & $3.463,34$ & 9,81 \\
SAFE 3 & $9.050,66$ & 21,68 & $6.633,33$ & 33,54 & $2.417,32$ & 11,00 \\
SAFE 4 & $15.214,47$ & 38,37 & $14.175,33$ & 57,64 & $1.039,14$ & 6,90
\end{tabular}

7 É importante ressaltar que neste caso, os custos foram classificados de acordo com a metodologia de Hoffman et al. (1986), na qual os custos são divididos em fixos e variáveis e sua soma, necessariamente, obtém-se o custo total de produção. Também se ressalta que segundo esta classificação, as depreciações são um tipo de custo fixo (as depreciações estão somadas como um custo fixo) e os valores de consumo intermediário e divisão do valor agregado, foram separados em fixos e variáveis, de acordo com os conceitos do autor referido. 


\begin{tabular}{ccccccc} 
SAFE 5 & $11.949,14$ & 48,77 & $10.680,00$ & 62,54 & $1.269,14$ & 17,09 \\
SAFE 6 & $4.238,10$ & 13,31 & $3.048,40$ & 63,24 & 0,00 & 0,00 \\
SAFE 7 & $8.494,33$ & 20,28 & $7.190,00$ & 42,03 & $1.304,33$ & 5,26 \\
SAFE 8 & $9.275,00$ & 47,20 & $7.136,00$ & 76,31 & $2.139,00$ & 20,77 \\
SAFE 9 & $8.607,69$ & 32,42 & $6.795,33$ & 61,74 & $1.812,35$ & 11,66 \\
SAFE 10 & $56.610,54$ & 7,53 & $26.090,00$ & 64,01 & $30.520,54$ & 4,29 \\
SAFE 11 & $19.228,04$ & 14,42 & $13.793,33$ & 34,50 & $5.434,70$ & 5,82 \\
SAFE 12 & $64.617,48$ & 12,26 & $49.617,34$ & 50,92 & $15.000,14$ & 3,49 \\
\hline Média & $\mathbf{1 9 . 5 0 8 , 9 4}$ & $\mathbf{2 5 , 9 7}$ & $\mathbf{1 3 . 8 6 3 , 8 1}$ & $\mathbf{5 5 , 4 4}$ & $\mathbf{5 . 5 4 5 , 9 8}$ & $\mathbf{8 , 6 8}$ \\
\hline
\end{tabular}

Fonte: Pesquisa NEA (Banco de Dados Agregado, 2015).

Com base nos dados da Tabela 3 é possível verificar que o maior custo associado à formalização institucional dos SAFEs está vinculado a compor a infra estrutura física das propriedades, onde as depreciações dos bens de capital fixo são a maior parcela de custos. Nota-se, também, que a diferença em termos dos custos variáveis é pequena nas duas situações, não chegando a $10 \%$. Isso é devido às propriedades familiares não modificarem muito este tipo de custo com insumos e serviços, nas duas situações. Além de muitos destes serem produzidos internamente aos sistemas ecológicos, desenvolvendo uma agricultura mais econômica, como a literatura tem denominado (PLOEG, 2008).

Segundo a Tabela 4 o custo médio para formalizar uma experiência é de $R \$ 5.325,36$, correspondendo a percentual de $8,65 \%$ dos CT. Contudo, estes são valores médios, pois há grande variação dos valores entre as iniciativas. Por exemplo, já que não se analisa cada iniciativa em específico, observa-se que no SAFE 8 (uma associação de apicultores que produz mel), o valor de $\mathrm{R} \$ 5.445,00$ é muito próximo à média antes referida e o custo percentual da formalização chega a quase $30 \%$ dos CT (27,71\%). Veja que neste caso em específico, os custos de formalização são altos e possivelmente podem desencorajar a legalização da experiência pelas famílias associadas.

Tabela 4. Custos de formalização institucional e da Certificação Orgânica (CO) Auditada e Participativa em relação ao Custo Total (CT)

\begin{tabular}{c|c|c|c|c}
\hline SAFEs & $\begin{array}{c}\text { Formalização } \\
\text { (R\$) }\end{array}$ & $\begin{array}{c}\text { Formalização/CT } \\
\text { (\%) }\end{array}$ & $\begin{array}{c}\text { CO } \\
\text { Participativa/CT } \\
\text { (\%) }\end{array}$ & $\begin{array}{c}\text { CO } \\
\text { Auditada/CT } \\
\text { (\%) }\end{array}$ \\
\hline SAFE 1 & $5.289,10$ & 11,93 & 3,25 & 5,75 \\
SAFE 2 & $4.500,61$ & 8,39 & 2,68 & 4,75 \\
SAFE 3 & $2.753,78$ & 6,60 & 3,45 & 6,11 \\
SAFE 4 & $2.560,45$ & 6,46 & 3,63 & 6,43
\end{tabular}




\begin{tabular}{ccccc} 
SAFE 5 & $3.042,84$ & 12,42 & 5,88 & 10,41 \\
SAFE 6 & $2.572,43$ & 8,08 & 4,52 & 8,01 \\
SAFE 7 & $4.006,40$ & 9,56 & 3,44 & 6,09 \\
SAFE 8 & $5.445,00$ & 27,71 & 7,33 & 12,98 \\
SAFE 9 & $1.482,10$ & 5,58 & 5,42 & 5,42 \\
SAFE 10 & $22.708,93$ & 3,02 & 0,19 & 0,34 \\
SAFE 11 & $4.079,54$ & 3,06 & 1,08 & 1,91 \\
SAFE 12 & $5.463,18$ & 1,04 & 0,27 & 0,48 \\
\hline Média & $\mathbf{5 . 3 2 5 , 3 6}$ & $\mathbf{8 , 6 5}$ & $\mathbf{3 , 4 3}$ & $\mathbf{5 , 7 2}$ \\
\hline
\end{tabular}

Fonte: Pesquisa NEA (Banco de Dados Agregado, 2015).

Em outro extremo, tem-se o exemplo do SAFE 12 (é uma unidade de processamento de erva mate). Observa-se que seu custo de formalização é de $R \$ 5.463,18$, também muito próximo à média acima discutida; entretanto, o impacto do processo de formalização no seu CT é de apenas 1,04\%. Possivelmente e comparativamente ao SAFE 8, esta iniciativa possui maiores possibilidades de poder arcar com os custos de formalização, que são considerados baixos em relação aos seus CT e a média dos SAFEs.

Os dados da Tabela 4 e a comparação destas duas experiências acima, nós leva a formular que o processo de formalização institucional de um SAFE é dependente de diversos fatores, realidades socioeconômicas e ambientais existentes, podendo ser viável ou não, economicamente, dependendo da situação financeira específica de cada iniciativa. Alguns dos principais fatores implicados na tomada de decisão dos agricultores sobre este processo, levando em conta os custos são: a existência de uma escala mínima de produção e processamento de alimentos, tipo de sistema produtivo adotado, exigências específicas por cadeia produtiva (custos específicos por tipo de produto e estabelecimento), apoio das políticas públicas ao setor agroindustrial e ecológico, mercados construídos para a venda dos produtos, rentabilidade aferida pela experiência, entre outros fatores, como a bibliografia da área evidencia (KOESLING et al, 2012; GAZOLLA, 2014).

Além disso, estes custos para legalizar as experiências possivelmente estejam subdimensionados em alguns casos, já que em várias situações durante a pesquisa de campo encontrou-se iniciativas em que o poder público apoia os agricultores lhes prestando vários 
serviços que não são cobrados. Exemplos disso seriam os trabalhos desenvolvidos gratuitamente pelo Serviço de Inspeção Municipal (SIM), profissionais da EMATER ou Prefeituras que atuam na assistência técnica e Alvará de Funcionamento. Há também fornecimento de código de barras ou mesmo isenção de impostos devido estes agricultores estarem participando do Programa de Agroindústria Familiar do RS (PAF/RS), entre outros exemplos que se poderia citar. Estes custos que são cobertos pelo Estado, em diferentes níveis, não foram computados junto às experiências.

Ainda na Tabela 4 é possível observar, dentro dos custos de formalização, a parcela correspondente aos custos da certificação orgânica (CO), nos formatos auditado e participativo. No primeiro formato, os custos médios por SAFE ficam em $\mathrm{R} \$$ 2.550,00, correspondendo a 5,72\% dos CT. No formato participativo, por exemplo, pela Rede Ecovida de Agroecologia, que foi usada como base do cálculo, os valores figuram em torno de $\mathrm{R} \$ 1.440,00$ por iniciativa, correspondendo a um percentual de 3,43\% do CT. Em termos absolutos, a diferença entre os dois tipos de certificações é de $R \$ 1.110,00$, sendo $56,47 \%$ menor no caso do tipo participativa. Este tipo de certificação também reduz o percentual sobre o custo total desta atividade, sendo, em média, 2,29\% menor.

A certificação participativa geralmente é realizada pelos próprios consumidores dos alimentos orgânicos, juntamente com técnicos que assessoram os agricultores. Devido ela ser considerada uma certificação informal e tripartite (agricultores - consumidores - técnicos) ela apresenta custos abaixo da auditada. Contudo, neste tipo de certificação com controle social, os alimentos só podem ser vendidos através de cadeias curtas aos próprios consumidores que auxiliam na mesma, não podendo ser comercializados em pontos de comércio formais, que exigem o formato auditado (RADOMSKI, 2015). Na prática, a forma participativa tem-se mostrado vantajosa aos agricultores familiares, devido muitos terem relações de proximidade social com os consumidores e possuírem poucos recursos disponíveis para entrar no sistema auditado (WILKINSON, 2008).

$\mathrm{Na}$ Tabela 5 são apresentadas as diferenças dos indicadores de desempenho econômico das iniciativas, como Margem Bruta (MB), Renda Agroindustrial (RAI) e o Índice de Eficiência Econômica (IEE), de forma 
comparativa entre a situação formal e informal. No caso da MB, esta é obtida a partir dos valores da Produção Bruta (PB), diminuídos os custos variáveis de produção (CV). É possível observar que a MB média das iniciativas na situação informal é maior em quase 7 mil reais (R\$ $6.994,96)$, correspondendo a diferenças percentuais em torno de $7 \%$ $(6,90 \%)$ maiores. Estes valores, apesar de significativos, não são tão elevados como no caso da RAI.

A diferença de valores da RAl, em média, é de $R \$ 19.508,94$, correspondendo a um aumento de $30 \%$ na situação informal (30,47\%). Entretanto, há uma grande heterogeneidade de situações, por exemplo, só para citar dois casos, já que não se discute todos em particular. Em algumas situações a RAl pode aumentar mais de $100 \%$ sem a formalização, como é o caso do SAFE 4 (derivados de cana) (aumento de 109,03\%), levantando a hipótese, que neste sistema produtivo os custos de formalização, possam ser mais elevados do que em outros. Já no SAFE 10 (frangos coloniais e diversificado) o impacto da formalização é menor sobre o aumento da RAI, em torno de 10\% (9,70\%).

Também se calculou o Índice de Eficiência Econômica (IEE) para as iniciativas, nos dois formatos (formal e informal) (Tabela 5). Segundo Hoffman et al. (1986), o IEE é um índice que descreve a relação entra a Produção Bruta (PB) e o Custo Total (CT) $(\mathrm{IEE}=\mathrm{PB} / \mathrm{CT})$, que ajuda a visualizar se uma determinada atividade ou unidade de produção encontra-se na situação de rentabilidade, equilíbrio ou de prejuízo econômico ${ }^{8}$. O IEE formal é maior do que 1,0 em todos os SAFEs, mostrando que as experiências estão possuindo rentabilidade maior do que seus custos. Em média, as propriedades possuem um IEE de 2,30, demonstrando que a PB cobre mais de duas vezes os custos de produção.

\footnotetext{
8 O IEE é interpretado da seguinte forma, segundo três situações: a) IEE > 1,0 - O SAFE está possuindo rentabilidade maior do que os custos; b) IEE $=0,0$ - O SAFE está em situação de equilíbrio entre rentabilidade e custos; c) IEE $<1,0$ - O SAFE está tendo custos de produção maiores do que a rentabilidade na atividade. Como é um índice, o mesmo não possui uma unidade de medida. Para maiores detalhes ver Hoffman et al. (1989).
} 
Tabela 5. Diferença de Margem Bruta (MB), Renda Agroindustrial (RAI) e Índice de Eficiência Econômica (IEE) entre as situações de formalidade e

\begin{tabular}{|c|c|c|c|c|c|c|c|}
\hline SAFEs & $\begin{array}{c}M B \\
\text { (R\$) }\end{array}$ & $\begin{array}{l}\text { MB } \\
(\%)\end{array}$ & $\begin{array}{l}\text { RAI } \\
\text { (R\$) }\end{array}$ & $\begin{array}{l}\text { RAI } \\
(\%)\end{array}$ & $\begin{array}{c}\text { IEE } \\
\text { Formal }\end{array}$ & $\begin{array}{c}\text { IEE } \\
\text { Informa } \\
\text { I }\end{array}$ & $\begin{array}{c}\text { Dif. IEE } \\
(I-F)\end{array}$ \\
\hline SAFE 1 & $2.151,79$ & 3,03 & $13.815,12$ & 25,85 & 2,21 & 3,20 & 1,00 \\
\hline SAFE 2 & $3.463,34$ & 2,90 & $13.006,67$ & 12,86 & 2,89 & 3,81 & 0,92 \\
\hline SAFE 3 & $2.417,32$ & 2,64 & $9.050,66$ & 12,61 & 2,72 & 3,47 & 0,75 \\
\hline \multirow{2}{*}{ SAFE 4} & $14.106,1$ & & & & & & \\
\hline & 7 & 36,59 & $15.214,47$ & 109,03 & 1,35 & 2,19 & 0,84 \\
\hline SAFE 5 & $1.269,14$ & 2,66 & $11.949,14$ & 38,95 & 2,25 & 4,40 & 2,14 \\
\hline SAFE 6 & $1.189,70$ & 4,11 & $4.238,10$ & 17,58 & 1,76 & 2,03 & 0,27 \\
\hline SAFE 7 & $4.435,34$ & 10,59 & $8.494,33$ & 44,62 & 1,45 & 1,82 & 0,37 \\
\hline SAFE 8 & $2.139,00$ & 2,53 & $9.275,00$ & 12,36 & 4,82 & 9,13 & 4,31 \\
\hline SAFE 9 & $1.812,35$ & 2,53 & $8.607,69$ & 14,19 & 3,29 & 4,86 & 1,58 \\
\hline \multirow{2}{*}{ SAFE 10} & $30.520,5$ & & & & & & \\
\hline & 4 & 4,89 & $56.610,54$ & 9,70 & 1,78 & 1,92 & 0,14 \\
\hline SAFE 11 & $5.434,70$ & 3,69 & $19.228,04$ & 17,95 & 1,80 & 2,11 & 0,30 \\
\hline \multirow{2}{*}{ SAFE 12} & $15.000,1$ & & & & & & \\
\hline & 4 & 6,61 & $64.617,48$ & 49,92 & 1,25 & 1,42 & 0,17 \\
\hline Média & $6.994,96$ & 6,90 & $19.508,94$ & 30,47 & 2,30 & 3,36 & 1,07 \\
\hline
\end{tabular}

Fonte: Pesquisa NEA (Banco de Dados Agregado, 2015). 
Já na situação de informalidade, o IEE de todas as iniciativas é maior, devido ser descontado parte dos custos de produção, da parcela de legalização institucional. Em média, o IEE fica em 3,36, demonstrando que as experiências são capazes de remunerar mais de três vezes os custos de produção que possuem. Nesta situação, a diferença de rentabilidade econômica dos sistemas produtivos é maior, em média, com um IEE de 1,07, evidenciando que em situações informais, as atividades agroindustriais ecológicas podem remunerar em mais de uma vez seus custos de produção.

De maneira geral, observa-se que manter as iniciativas na informalidade faz os agricultores auferirem maiores margem bruta, renda agroindustrial e IEE na atividade, devido, sobretudo, os fatores mencionados anteriormente, que são a diminuição dos custos com depreciações do capital fixo e pagamentos de impostos e taxas ao Estado. Em outros casos, a explicação pode estar na escala, pois iniciativas com escalas maiores podem diluir seus custos de formalização por unidade de alimentos ecológicos produzidos. Isso sugere, ser necessário aos SAFEs avaliarem e operarem segundo uma escala mínima produtiva (que seria específica e poderia ser definida para cada caso), para que sejam viáveis economicamente dentro de um ambiente institucional formal, já que a informalidade traz vários entraves ao desenvolvimento as experiências como estudos já apontaram (MALUF, 2004; MIOR, 2005; WILKINSON, 2008)9.

\section{Comparando cadeias produtivas: a situação formal e informal em perspectiva}

Nesta seção comparam-se as principais cadeias produtivas presentes nas experiências, de forma a evidenciar seus indicadores de custos e desempenho econômico. As comparações são desenvolvidas por unidade de área e per capita. Neste sentido, a Tabela 6 apresenta as diferenças, por área (R\$/ha) do Custo Variável (CV), Custo Fixo (CF) e Custo Total (CT) entre as cadeias existentes.

\footnotetext{
9 Não se está aludindo que as iniciativas devam ficar na informalidade, pois se sabe que isto, em alguns casos, representa riscos de segurança alimentar aos consumidores dos alimentos. O que o trabalho quer mostrar, simulando as duas situações (formal informal), são os custos e rendimentos associados a cada uma em particular.
} 
Em média as experiências possuem um custo variável menor em $\mathrm{R} \$ 339,86 /$ ha em situação informal, o que corresponde a $10,32 \%$ dos custos totais. Esta diferença é pequena, quando comparada com a dos custos fixos e mesmo os totais de produção. Os custos fixos diminuem $\mathrm{R} \$ 1.084,90$ / ha, sendo $143,73 \%$ menores na situação de informalidade. Estes dados mostram que o grande diferencial em termos de custos de produção para viabilizar a legalização das experiências está nos custos fixos, que são os que oneram os agricultores. È a montagem da infraestrutura produtiva em termos de planta, máquinas e equipamentos agroindustriais os principais custos fixos que são impeditivos a formalização, como havia sido já discutido na seção anterior.

Há também grandes diferenças nos CV e CF por cadeia de produção. Por exemplo, os CV são apenas $3,62 \%$ menores na informalidade no SAFE 12 (erva-mate, peixes e grãos) até valores de $26,21 \%$ no SAFE 8 (mel). Os custos fixos também possuem uma amplitude muito grande, sendo $50,47 \%$ menores na situação de informalidade no SAFE 3 (erva mate ecológica de barbaquá) até mais de $322,17 \%$ no SAFE 8 (mel). Nestes casos, usados como exemplos pontuais, as cadeias produtivas da erva mate são as que menos custos variáveis e fixos baixam na informalidade. Já a cadeia do mel é a que mais consegue economizar em custos quando mantem-se na informalidade.

Já a diferença dos custos totais médios por área é de $\mathrm{R} \$$ $1.424,76 /$ ha, correspondendo a quase $40 \%$ menores na informalidade $(39,96 \%)$, evidenciando o peso que a formalização coloca para os sistemas produtivos ecológicos. Neste montante de $40 \%$ maiores por hectare, entende-se a decisão de muitos agricultores em desistir da legalização de suas experiências, pois os desembolsos financeiros são elevados. A diferença de CT é maior na cadeia da cana e mel (SAFE 5 e 8) e menores (menos econômicos) nas cadeias de frangos coloniais e de erva mate associada a peixes e grãos (SAFEs 10 e 12).

Tabela 6. Diferença por área ( $R \$ /$ ha) dos Custos Variáveis (CV), Custos Fixos (CF) e Custo Total (CT) entre as situações de formalidade e informalidade

\begin{tabular}{c|c|c|c|c|c|c}
\hline & $\begin{array}{c}\text { CV } \\
\text { SAFEs }\end{array}$ & $\begin{array}{c}\text { CV } \\
(\%)\end{array}$ & $\begin{array}{c}\text { CF } \\
(\mathbf{R} \$)\end{array}$ & $\begin{array}{c}\text { CF } \\
(\%)\end{array}$ & $\begin{array}{c}\text { CT } \\
(\mathbf{R} \$)\end{array}$ & $\begin{array}{c}\text { CT } \\
(\%)\end{array}$ \\
\hline SAFE 1 (Mel, frutas, peixe; & 457,83 & 8,72 & $2.481,56$ & 200,3 & $2.939,39$ & 45,2
\end{tabular}




\begin{tabular}{|c|c|c|c|c|c|c|}
\hline div.) & & & & 2 & & 8 \\
\hline SAFE 2 (Der. milho e gado & & & & 108,6 & & 32,0 \\
\hline corte) & 277,07 & 10,88 & 763,47 & 1 & $1.040,53$ & 2 \\
\hline SAFE 3 (Er. mate eco. & & & & & & 27,6 \\
\hline barbaquá) & 179,06 & 12,36 & 491,36 & 50,47 & 670,42 & 8 \\
\hline SAFE 4 (Der. cana; & & & & 136,0 & & 62,2 \\
\hline diversif.) & 112,95 & 7,41 & $1.540,80$ & 8 & $1.653,75$ & 5 \\
\hline SAFE 5 (Derivados de & & & & 166,9 & & 95,1 \\
\hline cana) & 317,29 & 20,62 & $2.670,00$ & 3 & $2.987,29$ & 8 \\
\hline SAFE 6 (Der. frutas/hort.; & & & & 172,0 & & 15,3 \\
\hline div.) & 113,30 & 4,61 & 290,32 & 1 & 403,63 & 6 \\
\hline SAFE 7 (Der. uva; & & & & & & 25,4 \\
\hline diversif.) & 55,27 & 5,56 & 304,66 & 72,49 & 359,93 & 4 \\
\hline \multirow[t]{2}{*}{ SAFE 8 (somente mel) } & & & & 322,1 & & 89,4 \\
\hline & 427,80 & 26,21 & $1.427,20$ & 7 & $1.855,00$ & 0 \\
\hline SAFE 9 (Der. cana e & & & & 161,3 & & 47,9 \\
\hline frutas; div.) & 120,82 & 13,20 & 453,02 & 8 & 573,85 & 7 \\
\hline SAFE 10 (Frangos & & & & 177,8 & & \\
\hline coloniais; div.) & $1.623,43$ & 4,48 & $1.387,77$ & 5 & $3.011,20$ & 8,14 \\
\hline SAFE 11 (Der. cana; & & & & & & 16,8 \\
\hline grãos) & 120,77 & 6,18 & 306,52 & 52,66 & 427,29 & 5 \\
\hline SAFE 12 (Er. mate, peixes, & & & & 103,7 & & 13,9 \\
\hline grãos) & 272,73 & 3,62 & 902,13 & 6 & $1.174,86$ & 8 \\
\hline \multirow[t]{2}{*}{ Média } & & & & 143,7 & & 39,9 \\
\hline & 339,86 & 10,32 & $1.084,90$ & 3 & $1.424,76$ & 6 \\
\hline
\end{tabular}

Fonte: Pesquisa NEA (Banco de Dados Agregado, 2015).

Ainda sobre os dados da Tabela 6, evidencia-se que a diversificação possui efeitos diferentes sobre os custos por área. Em algumas cadeias produtivas ela ajuda a baixar os custos para formalizar as experiências (frangos coloniais; uva; frutas/hortaliças), já em outras, ocorre justamente o contrário, elevação dos valores por área (mel com frutas e peixes, cana; cana e frutas), mostrando não haver um efeito claro em uma única direção da diversificação e que isso depende da cadeia produtiva analisada.

Já na Tabela 7 visualiza-se a diferença de Valor Agregado Líquido (VAL) e Renda Agroindustrial (RAl) entre as situações de formalidade e informalidade, por área ( $\mathrm{R} \$ / \mathrm{ha})$. Os dados mostram que a diferença de VAL é R\$607,08/ha, perfazendo 9,42\%, em média, maiores na informalidade. O VAL possui grande variação por cadeia produtiva. A seguir discutem-se alguns exemplos, já que não é possível discutir 
todos os casos em específico. Nas cadeias da cana com diversificação $(37,06 \%)$, somente cana $(16,72 \%)$ e uva com diversificação $(11,60 \%)$ são os sistemas produtivos onde a diferença é maior, chegando a quase 2 mil reais de $\mathrm{VAL} /$ ha no SAFE 5 (R\$ 1.915,00). Há outras situações em que a diferença de $\mathrm{VAL} / \mathrm{ha}$ é menor, por exemplo, nas cadeias dos frangos coloniais com diversificação (0,61\%), derivados de frutas/hortaliças com diversificação $(1,76 \%)$ e as cadeias dos SAFEs 2,3 e 8 que estão entre 4 a $5 \%$ (gado de corte, erva mate e mel).

O aumento do VAL é em torno de $10 \%$ de ganhos financeiros, em média, com a não formalização do sistema agroindustrial ecológico. Este valor não é uma rentabilidade tão elevada. Esta diferença é bem maior, com a renda agroindustrial, que praticamente dobra, comparativamente ao VAL (Tabela 7). A RAl é maior na situação informal, em média, de $\mathrm{R} \$ 1.424,68 / \mathrm{ha}$, correspondendo a um percentual de 20,99\%, mostrando que os sistemas ecológicos aferem maiores rendas por área na situação informal.

Tabela 7. Diferenças por área ( $\mathrm{R} \$ /$ ha) do Valor Agregado Líquido (VAL) e Renda Agroindustrial (RAl) entre as situações de formalidade e

\begin{tabular}{l|c|c|c|c}
\multicolumn{5}{c}{ informalidade } \\
\hline SAFEs & VAL (R\$) & VAL (\%) & RAI (R\$) & RAI (\%) \\
\hline SAFE 1 (Mel, frutas, peixe; div.) & $1.390,07$ & 9,69 & $2.939,39$ & 20,54 \\
SAFE 2 (Der. milho e gado corte) & 410,67 & 4,50 & $1.040,53$ & 11,39 \\
SAFE 3 (Er. mate eco. barbaquá) & 291,36 & 4,95 & 670,42 & 11,38 \\
SAFE 4 (Der. cana; diversif.) & $1.263,62$ & 37,06 & $1.653,75$ & 52,16 \\
SAFE 5 (Derivados de cana) & $1.915,00$ & 16,72 & $2.987,29$ & 28,03 \\
SAFE 6 (Der. frutas/hort.; div.) & 47,47 & 1,76 & 402,68 & 14,92 \\
SAFE 7 (Der. uva; diversif.) & 135,59 & 11,60 & 359,93 & 30,85 \\
SAFE 8 (somente mel) & 766,00 & 4,54 & $1.854,98$ & 11,00 \\
SAFE 9 (Der. cana e frutas; div.) & 357,02 & 8,38 & 573,85 & 14,19 \\
SAFE 10 (Frangos coloniais; div.) & 212,77 & 0,61 & $3.011,20$ & 8,85 \\
SAFE 11 (Der. cana; grãos) & 217,30 & 6,29 & 427,29 & 15,22 \\
SAFE 12 (Er. mate, peixes, grãos) & 278,12 & 6,91 & $1.174,86$ & 33,30 \\
\hline Média & 607,08 & 9,42 & $1.424,68$ & 20,99 \\
\hline
\end{tabular}

Fonte: Pesquisa NEA (Banco de Dados Agregado, 2015).

Essa diferença de valores da renda entre as situações de formalidade e informalidade é diferenciada entre as cadeias produtivas. As maiores diferenças por área são encontradas nos sistemas produtivos de cana com diversificação $(52,16 \%)$, uva com diversificação 
$(30,85 \%)$ e somente cana $(28,03 \%)$, evidenciando que nestas três cadeias o impacto financeiro da legalização é maior sobre os rendimentos dos agricultores. As cadeias em que esta diferença por área é menor, ficando em torno de $10 \%$ são: frangos coloniais com diversificação (8,85\%), mel (11\%), erva mate de barbaquá $(11,38 \%)$ e derivados de milho com gado de corte $(11,39 \%)$. Nestas cadeias, o peso da formalização sobre a renda é menor, sendo mais fácil aos agricultores formalizarem suas iniciativas.

Os dados contidos na Tabela 7 também permite verificar que a diversificação dos sistemas ecológicos não necessariamente diminui a exigência de renda por área para as famílias formalizarem suas experiências. Nas cadeias de frangos coloniais, cana com frutas e derivados de frutas/hortaliças com diversificação associada à formalização impacta menos sobre a rentabilidade das famílias, entre 8 a $15 \%$ por hectare. Já em outras cadeias, por exemplo, mel com frutas e peixes, derivados de uva e cana, a diversificação eleva a diferença de renda por hectare na situação informal, sendo que está pode variar de em torno de 20 até mais de $50 \%$ da renda dos sistemas ecológicos.

$\mathrm{Na}$ Tabela 8 pode-se visualizar a diferença per capita (R $\$ /$ UTHs) do Valor Agregado Líquido (VAL) e Renda Agroindustrial (RAl) entre as situações de formalidade e informalidade. Isso permite saber o valor agregado gerado por pessoa ocupada nas diferentes cadeias produtivas quando o SAFE é formal ou informal. Neste sentido, a diferença do VAL médio per capita entre as duas situações é de $R \$ 1.861,42$, o que corresponde a $11,18 \%$, sendo maior quando as cadeias produtivas são mantidas informais.

É claro que há variações de valores por cadeias. Somente para exemplificar as maiores e menores diferenças, já que não se analisam todos os casos. Na cadeia de derivados de cana com diversificação está diferença per capita é de $\mathrm{R} \$ 3.875,11 / \mathrm{UTH}(58,88 \%)$, demonstrando ser a cadeia da cana com diversificação a que maior valor agregado líquido per capita aferiria se mantida na informalidade institucional. No extremo oposto, as cadeias do frango colonial com diversificação $(0,61 \%)$, derivado de milho com gado de corte $(4,5 \%)$, mel $(4,54 \%)$ e erva-mate ecológica de barbaquá (4,95\%) são as que o processo de legalização teria menores efeitos sobre seu VAL/UTH. 
Já a diferença de renda agroindustrial per capita média dos sistemas ecológicos é de R\$6.534,96/UTH, correspondendo a um percentual de $25,58 \%$ maior, nos casos das iniciativas serem mantidas informais. Veja que estes valores são um pouco mais elevados dos por área, discutidos na Tabela 7 acima, percentualmente, em torno de 5\% mais altos, indicando maiores diferenças per capitas do que por hectare.

Estas diferenças de RAI/UTHs não são equânimes entre cadeias de produção. Note que, por exemplo, já que não se discute todos os doze conjuntos de sistemas ecológicos, a cadeia da cana associada à diversificação a renda per capita seria mais de $100 \%$ maior, se mantida informal (109,03\%), correspondendo a R\$5.071,49/UTH. Na maioria das cadeias (em dez de doze analisadas) as diferenças dos valores são bem mais baixas (RAl per capita varia de 10 a $30 \%$ maior na informalidade). Contudo, há cadeias em que a diferença da RAI/UTH é menor do que $10 \%$, sendo cadeias produtivas em que o peso do processo de formalização seria menos sentido pelos agricultores (frangos coloniais com diversificação expenderia somente $8,85 \%$ da sua $\mathrm{RAl}$ /per capita para se legalizar). 
Tabela 8. Diferença per capita (R\$/UTHs) do Valor Agregado Líquido (VAL) e da Renda Agroindustrial (RAI) entre as situações de formalidade e informalidade

\begin{tabular}{c|c|c|c|c}
\hline SAFEs & VAL (R\$) & VAL (\%) & RAI (R\$) & RAI (\%) \\
\hline SAFE 1 (Mel, frutas, peixe; div.) & $3.266,67$ & 9,69 & $6.907,56$ & 20,54 \\
SAFE 2 (Der. milho e gado corte) & $1.711,11$ & 4,50 & $4.335,56$ & 11,39 \\
SAFE 3 (Er. mate eco. barbaquá) & 983,33 & 4,95 & $2.262,66$ & 11,38 \\
& & & & 109,0 \\
SAFE 4 (Der. cana; diversif.) & $3.875,11$ & 58,88 & $5.071,49$ & 3 \\
SAFE 5 (Derivados de cana) & $1.915,00$ & 16,72 & $2.987,29$ & 28,03 \\
SAFE 6 (Der. frutas/hort.; div.) & 249,20 & 1,76 & $2.114,05$ & 14,92 \\
SAFE 7 (Der. uva; diversif.) & $1.600,00$ & 11,60 & $4.247,17$ & 30,85 \\
SAFE 8 (somente mel) & 957,50 & 4,54 & $2.318,72$ & 11,00 \\
SAFE 9 (Der. cana e frutas; div.) & $1.785,11$ & 7,73 & $2.869,23$ & 12,42 \\
SAFE 10 (Frangos coloniais; div.) & $1.000,00$ & 0,61 & $14.152,64$ & 8,85 \\
SAFE 11 (Der. cana; grãos) & $2.444,58$ & 6,29 & $9.614,02$ & 15,22 \\
SAFE 12 (Er. mate, peixes e grãos) & $2.549,44$ & 6,91 & $21.539,16$ & 33,30 \\
\hline Média & $1.861,42$ & 11,18 & $6.534,96$ & $\mathbf{2 5 , 5 8}$ \\
\hline
\end{tabular}

Fonte: Pesquisa NEA (Banco de Dados Agregado, 2015).

Novamente, como discutido acima no caso da renda por área, nos indicadores de desempenho econômico per capita, a diferença dos valores devido ao efeito da diversificação das propriedades são randômicos. Como exemplo, mencionam-se a cadeia de frangos coloniais, derivados de cana com frutas e derivados de frutas e hortaliças, em que a diferença entre as situações formal - informal varia de 8 a 15\% da renda/UTH, sendo experiências que desembolsariam menos recursos, caso se formalizassem. Já a cadeia de derivados de cana seria campeã, pois a diferença assume os maiores valores, atingindo mais de $100 \%$ de sua renda per capita (109,03\%). Outras cadeias figuram com diferenças de valores em torno de 15 a $30 \%$ da RAI/UTH (mel com frutas e peixe; derivados de uva).

$\mathrm{Na}$ Tabela 9, tem-se a diferença de Ponto de Nivelamento (PN) e Nível de Reprodução Simples (NRS) entre as situações de formalidade e informalidade. O ponto de nivelamento pode ser definido como o valor de margem bruta necessária para cobrir os custos de produção variáveis da experiência. É o ponto em que a margem bruta se nivela com os custos variáveis, de forma equânime. Pelos dados da Tabela 9, observa- 
se que a diferença de valores do PN médio dos SAFEs é de $R \$$ $28.245,62$, que corresponde em percentuais, em torno de $15 \%$ dos valores da margem bruta das iniciativas (14,99\%). Dito de outra forma, em média, é de $15 \%$ a diferença dos valores de margem bruta gerados pelas iniciativas para se atingir o PN, que é de 28 mil reais. 
Tabela 9. Diferença de Ponto de Nivelamento (PN) e Nível de Reprodução Simples (NRS) entre as situações de formalidade e informalidade

\begin{tabular}{ccc|ccc}
\hline SAFEs & PN (R\$) & PN (\%) & $\begin{array}{c}\text { PN c/ NRS } \\
\text { (R\$) }\end{array}$ & $\begin{array}{c}\text { PN c/ NRS } \\
\text { (\%) }\end{array}$ \\
\hline SAFE 1 (Mel, frutas, peixe; div.) & $16.312,47$ & 16,68 & $17.076,38$ & 17,47 \\
SAFE 2 (Der. milho e gado corte) & $12.683,28$ & 8,19 & $13.713,56$ & 8,86 \\
SAFE 3 (Er. mate eco. barbaquá) & $8.644,20$ & 7,61 & $9.844,96$ & 8,67 \\
SAFE 4 (Der. cana; diversif.) & $20.094,99$ & 37,48 & $21.125,84$ & 39,41 \\
SAFE 5 (Derivados de cana) & $12.531,96$ & 22,71 & $13.658,14$ & 24,75 \\
SAFE 6 (Der. frutas/hort.; div.) & $6.030,78$ & 10,78 & $7.468,89$ & 13,35 \\
SAFE 7 (Der. uva; diversif.) & $12.700,91$ & 20,85 & $13.805,91$ & 22,66 \\
SAFE 8 (somente mel) & $8.068,42$ & 8,52 & $9.112,78$ & 9,62 \\
SAFE 9 (Der. cana e frutas; div.) & $8.395,40$ & 9,62 & $9.242,70$ & 10,60 \\
SAFE 10 (Frangos coloniais; div.) & $57.286,16$ & 4,29 & $61.041,60$ & 4,57 \\
SAFE 11 (Der. cana; grãos) & $24.072,15$ & 10,01 & $25.168,24$ & 10,46 \\
SAFE 12 (Er. mate, peixes, grãos) & $152.126,73$ & 23,18 & $157.192,61$ & 23,95 \\
\hline Média & $\mathbf{2 8 . 2 4 5 , 6 2}$ & $\mathbf{1 4 , 9 9}$ & $\mathbf{2 9 . 8 7 0 , 9 7}$ & $\mathbf{1 6 , 2 0}$ \\
\hline
\end{tabular}

Fonte: Pesquisa NEA (Banco de Dados Agregado, 2015).

Essa diferença de valores do ponto de nivelamento é variável por cadeia de produção. Observa-se que em algumas cadeias, por exemplo, de derivados de milho com gado de corte, erva mate de barbaquá, mel, derivados de cana com frutas com diversificação e frangos com diversificação a diferença de valores do ponto de nivelamento é menor de $10 \%$, sendo cadeias produtivas que expendem menores proporções de sua margem bruta para se formalizar. Nas demais cadeias a diferença de valores do PN varia, aproximadamente, de 10 a 25\% da margem bruta, para cobrir os custos variáveis. Somente na cadeia de derivados de cana associada com diversificação é que o PN é maior de $35 \%$ dos valores da margem bruta $(37,48 \%)$, mostrando ser este sistema produtivo é o que maior de margem bruta seria consumida em um processo de legalização institucional.

Na Tabela 9 também é possível verificar a diferença entre as situações formais e informais das cadeias produtivas quando se adiciona ao PN os valores do Nível de Reprodução Simples (NRS). Segundo os dados da Tabela 9, nota-se que a diferença entre as duas situações (formal-informal) aumenta os valores do PN, porém, não de forma acentuada, sendo que o mesmo passa de 28 mil para 29 mil 
reais/ano/iniciativa. Em termos percentuais médios, o aumento também é pequeno, um pouco maior do que $1 \%$.

Estes dados evidenciam que os sistemas ecológicos de produção conseguem além de cobrir seus custos de produção, não desprendendo muito de sua margem bruta para isso (em média, seu PN utiliza apenas $15 \%$ da mesma), eles ainda dão conta de remunerar a força de trabalho familiar, caso este cálculo fosse incluído como custo de oportunidade das UTHs que trabalham nas propriedades. É claro que o número de trabalhadores atuantes nas propriedades foi reduzido para fins de cálculos, pois em uma situação informal utilizar-se-ia menos força de trabalho, bem como não se pagaria, por exemplo, INSS e outros encargos trabalhistas ao Estado.

\section{Considerações finais}

O trabalhou evidenciou os custos para formalizar sistemas de produção da agricultura de base ecológica, associados com processamento agroindustrial de produtos e alimentos. Os dados contribuem para o entendimento dos valores pagos pelos agricultores para formalizar suas propriedades com agroindústrias perante o Estado, em seus vários níveis federativos, levando em conta as diferentes dimensões das legislações agroalimentares (sanitária, jurídica, ambiental, trabalhista, fiscal, certificação orgânica, entre outras). Além disso, o trabalho procurou aferir as diferenças, em termos de custos e rendimentos econômicos, das duas situações das experiências - formal e informal.

De maneira geral, os dados mostram que do conjunto de custos de produção mensurados, as depreciações possuem maior peso no processo de formalização institucional dos sistemas ecológicos. Isto é devido a maior necessidade de investimentos em infraestrutura de produção nas propriedades, por exemplo, prédio da agroindústria, veículos de transporte, máquinas e equipamentos agroindustriais e agropecuários. Já no caso dos custos variáveis estes se compõem dos desembolsos que os agricultores realizam para pagar taxas, impostos, juros, salários, serviços, entre outras rubricas para o Estado e terceiros da sociedade, "dividindo" seus rendimentos com estes agentes econômicos. 
Em situação de informalidade o custo total das experiências reduz-se em torno de $25 \%$, sendo que a depreciação cai pela metade e o DVA é dividido por mais de quatro, evidenciando que nesta situação estes custos recuam sobremaneira nos sistemas de produção ecológicos. O mesmo ocorre quando se classificou os custos em fixos e variáveis. Os primeiros recuam em mais de $55 \%$, enquanto os segundos em torno de 9\%, evidenciando que os custos fixos pesam mais na formalização das iniciativas, como aludido a cima. Os custos variáveis não mudam muito entre as duas situações (formal-informal), devido os agricultores necessitarem de quase o mesmo conjunto de insumos e serviços dos mercados. Também, devido estes custos serem menores no dispêndio produtivo, pois muitos insumos e tecnologias serem gestados dentro das próprias propriedades rurais, como alguns autores tem demonstrado em estudos (PLOEG, 2008).

Em relação à formalização institucional das experiências aferiu-se os custos para implementá-la, chegando a valores em torno de $9 \%$ do custo total. Ou seja, do custo total dos sistemas produtivos, os agricultores expendem 9\% para se formalizar nas várias dimensões das legislações agroalimentares. Quando se calculou os custos da certificação orgânica, dentro do processo de formalização, chegou-se a valores médios de quase $6 \%$ dos custos totais em seu formato auditado e, em torno de $3,5 \%$ do custo total no caso da participativa. Estes são resultados importantes de pesquisa, pois se conseguiu verificar o peso da formalização no total dos custos de produção, bem como da certificação orgânica, evidenciando ser o formato participativo bem mais viável a realidade de agricultura familiar de base ecológica.

Em relação aos indicadores de desempenho dos sistemas produtivos, as informações mostram que na situação de informalidade institucional os ganhos econômicos são maiores. Segundo a pesquisa, a margem bruta aumenta em torno de $7 \%$, a RAI em 30\% e o IEE em mais de 1,0. Estes dados ajudam a entender por que muitas famílias optam por não formalizarem suas propriedades com agroindústrias associadas, pois se o fizeram aumentam custos e diminuem sua rentabilidade. Entretanto, estes são valores gerais e médios, pois quando se analisa a situação das cadeias de produção (rentabilidade por área e per capita) existentes dentro dos sistemas produtivos a realidade é muito heterogênea. 
A ideia não é a de aprofundar as conclusões em torno disso, mas os dados mostram, grosso modo, que a cadeia da cana de açúcar com diversificação da propriedade, derivados de cana e uva com diversificação seriam as que a diferença entre as situações formal e informal seriam maiores, em termos de valor agregado líquido e renda agroindustrial, tanto per capita quanto por área, evidenciando que se estas se mantivessem na informalidade aufeririam maiores rentabilidade. Dizendo de outra forma, o peso da legalização seria maior nestas cadeias produtivas ecológicas. A cadeia da cana associada à diversificação é onde se encontram as maiores diferenças entre as situações formal e informal, mostrando ser esta a cadeia mais onerosa em um processo de formalização institucional.

Em situação contrária a estas cadeias, tem-se a de derivados de milho com gado corte, erva mate ecológica de barbaquá, mel e frangos com diversificação as que possuem menores diferenças de valor agregado líquido e, especialmente, de renda agroindustrial entre as situações formal e informal. Neste caso, o peso de formalizar a estrutura de produção e os produtos destas cadeias produtivas seriam menos onerosos aos agricultores e seus sistemas ecológicos. Ressaltase que a cadeia de frangos coloniais com diversificação associada, seria a que menores valores expenderia na formalização institucional.

Outra conclusão importante é sobre o efeito da diversificação das propriedades, que para alguns autores tem sido considerada efetiva na reprodução social sustentável das famílias (ELLIS, 2000). Os dados de pesquisa evidenciam que o efeito da diversificação é randômico junto às experiências. Há cadeias em que a presença da mesma faz baixar custos de produção e aumenta a renda, por exemplo, na cadeia dos frangos coloniais. Em outras, ocorre justamente o contrário, como é o caso da cadeia da cana de açúcar. Isto mostra que os efeitos da diversificação não são claros ou, estão associados ao tipo de sistema ecológico e de cadeia produtiva que ela está presente.

Contudo, todas estas considerações são parciais e seriam necessários outros estudos, em outros contextos socioeconômicos e ambientais para compararem-se os dados com maior eloquência. Além disso, leva-se em conta os valores médios dos sistemas agroindustriais ecológicos, já que quando se analise os dados específicos das iniciativas, nota-se uma grande diversidade de situações. Neste sentido, 
alguns dos principais fatores implicados na tomada de decisão dos agricultores sobre formalizar suas experiências são: a existência de uma escala mínima de produção e processamento de alimentos, tipo de sistema produtivo adotado, exigências específicas por cadeia produtiva (custos específicos por tipo de produto e estabelecimento), apoio das políticas públicas ao setor agroindustrial e ecológico, peso da formalização sobre os custos totais, mercados construídos para a venda dos produtos, rentabilidade aferida pela experiência, entre outros fatores. 


\section{REFERÊNCIAS}

ALTIERI, M. Agroecologia: a dinâmica produtiva da agricultura sustentável. Editora da UFRGS: Porto Alegre. 4ª Edição, 2004.

BRANCHER, P. C. As faces da certificação de produtos orgânicos no Brasil: o caso do mercado da Região Metropolitana de Curitiba - PR. XLIII Congresso da Sociedade Brasileira de Economia, Sociologia e Administração Rural. Anais... 2005.

CHAYANOV, Alexander. La organización de la unidad económica campesina. Buenos Aires: Editora Nueva Vision, 1974.

DAROLT. M. R. Circuitos curtos de comercialização de alimentos ecológicos: reconectando produtores e consumidores. In: NIEDERLE, P. A.; ALMEIDA, L.; VEZZANI, F. M. (Orgs.) Agroecologia: práticas, mercados e políticas para uma nova agricultura. Editora Kairós: Curitiba. pp. 139170, 2013.

ELLIS, F. Rural livelihoods and diversity in developing countries. Oxford: Oxford University Press, 273p., 2000.

GAZOLLA, M. Conhecimentos, produção de novidades e ações institucionais: cadeias curtas das agroindústrias familiares. 292 f. 2012. Tese (Doutorado em Desenvolvimento Rural). Programa de PósGraduação em Desenvolvimento Rural, Universidade Federal do Rio Grande do Sul. Porto Alegre, 2012.

Redefinindo as agroindústrias no Brasil: uma conceituação baseada em suas "condições alargadas" de reprodução social. Revista IDeAS. v. 7, n. 2, p. 62-95, 2013.

Segurança alimentar e nutricional e agroindústrias familiares: políticas públicas e ações locais. Segurança Alimentar e Nutricional. Campinas, 21 (2): 527-540, 2014. 
GIDDENS, A.; BECK, U.; LASH, S. Modernização reflexiva: política, tradição e estética na ordem social moderna. Editora da USP: São Paulo. 1997.

GLISSMAN, S. R. Agroecologia: processos ecológicos em agricultura sustentável. Editora da UFRGS: Porto Alegre. 4ª Edição, 2009.

HOFFMAN, R. et al. Administração da empresa agrícola. Editora Biblioteca Pioneira. $6^{\mathrm{a}}$ Ed., 1989.

IBGE. Censo Agropecuário. Brasília: CD-Roan. 2006

LIMA, A. J. P. et al. Administração da unidade de produção familiar. modalidades de trabalho com agricultores. Editora UNIJUI: Ijui. $2^{\mathrm{a}}$ Edição, 1995.

LONG, N. Development sociology. actor perspectives. Routledge, $1^{\mathrm{a}}$ Edição, 285 p., 2001.

MALUF, R. S. Mercados agroalimentares e agricultura familiar no Brasil: agregação de valor, cadeias integradas e circuitos regionais. Revista Ensaios FEE. Porto Alegre, v. 25, nº 1, p. 299-322, 2004.

MARESCOTTI, A. Le dimensioni della tipicità dei produtti agroalimentare. In: Agenzia Regionale per lo Svillupo e l'Innovazione nel Settore Agricolo-Florestale (ARSIA) (Org.). Guida per la valorizzazione dei produtti agroalimentare tipici: concetti, metodi e strumenti. Manuale ARSIA. Regione Toscana: Firenze. p. 13-20, 125 p., 2006.

MAZOYER, M.; ROUDART, L. História das agriculturas do mundo: do Neolítico à crise contemporânea. Lisboa: Instituto Piaget, 2001.

MIOR, L. C. Agricultores familiares, agroindústrias e redes de desenvolvimento rural. Chapecó: Editora Argos, 338 p., 2005. 
NIEDERLE, P. A.; ALMEIDA, L.; VEZZANI, F. M. (Orgs.) Agroecologia: práticas, mercados e políticas para uma nova agricultura. Editora Kairós: Curitiba. 2013.

NIEDERLE, P. A.; RAULET, M. Agricultura familiar e mercados para produtos orgânicos: o desafio de integrar novos circuitos de comércio. Anais... 52 ${ }^{\circ}$ Congresso da Sociedade Brasileira de Economia, Sociologia e Administração Rural. Disponível em: < www.sober.org.br >. Goiânia, 2014.

OLIVEIRA, J. A. et al. Diagnóstico e potencial das agroindústrias familiares do Estado do Rio Grande do Sul. Relatório de Estudo Especial. Cooperativa dos Engenheiros Agrônomos de Santa Catarina. Florianópolis: SC, 100p., Abril de 2002.

PLOEG, J. D. van der. Camponeses e impérios alimentares: lutas por autonomia e sustentabilidade na era da globalização. Porto Alegre: Editora da UFRGS. Coleção Estudos Rurais, 372p., 2008.

KOESLING, M. et al. Farmers' reasons for deregistering from organic farming. Organic Agricultural. p. 1-14, 2012.

RADOMSKY, G. F. W. Certificação participativa e agricultura ecológica: rede, processos de inovação e conhecimentos locais. In: SCHNEIDER, S.; GAZOLLA, M. Os atores do desenvolvimento rural: perspectivas teóricas e práticas sociais. Porto Alegre: Editora da UFRGS. 2 ${ }^{\mathrm{a}}$ Edição, p. 235$251,2015$.

RAUPP, A. K. Políticas Públicas e Agroindústrias de Pequeno Porte da Agricultura Familiar. considerações de Experiências do Rio Grande do Sul. 245f. 2005. Dissertação (Mestrado em Desenvolvimento, Agricultura e Sociedade) - Programa de Pós-Graduação em Desenvolvimento, Agricultura e Sociedade, Universidade Federal Rural do Rio de Janeiro. Rio de Janeiro, 2005.

RENTING, H., MARSDEN, T., BANKS, J. Understanding alternative food networks: Exploring the role of short food supply chains in rural development. Environment and Planning. Wageningen, v. 35, p. 393$411,2003$. 
RODRIGUES, R. et al. "Drivers" de mudanças no sistema agroalimentar brasileiro. Parceria Estratégica. Brasília-DF, CGEE, Vol. 17, n 34, p.744, jan-jun 2012.

SAGE, C. The interconnected challenges for food security from a food regimes perspective: energy, climate and malconsumption. Journal of Rural Studies. Vol. 29, January, Pages 71-80, 2013.

SCALCO, A. R.; SERVI, R. G. Manutenção da certificação orgânica em produtores rurais. Revista em Agronegócios e Meio Ambiente. v.7, n.3, p. 515-534, set./dez. 2014.

SCHNEIDER, S. A pluriatividade na agricultura familiar. Porto Alegre: Editora da UFRGS, Coleção Estudos Rurais, 254p., 2003.

VASCONCELLOS, M. J. E. Pensamento sistêmico: o novo paradigma da ciência. Campinas: Papirus, 2006.

WANDERLEY, M. B. N. O mundo rural como um espaço de vida: reflexões sobre a propriedade da terra, agricultura familiar e ruralidade. Porto Alegre: Editora da UFRGS. $1^{\text {a }}$ edição. Série Estudos Rurais. 330p., 2009.

WESZ JÚNIOR, V. J. Políticas públicas de agroindustrialização: uma análise do Pronaf Agroindústria. In: CONGRESSO DA SOCIEDADE DE ECONOMIA, SOCIOLOGIA E ADMINISTRAÇÃO RURAL, 47., Porto Alegre. Anais... v.1, 2009, 21 p. 1 CD-ROM.

WILKINSON, J. Mercados, redes e valores: o novo mundo da agricultura familiar. Porto Alegre: Editora da UFRGS, Série Estudos Rurais. Programa de Pós-Graduação em Desenvolvimento Rural, 213 p., 2008.

Submetido em $21 / 12 / 2015$

Aprovado em 27/07/2016

Sobre os Autores 


\section{Marcio Gazolla}

Doutor em Desenvolvimento Rural. Professor da Universidade Tecnológica Federal do Paraná (UTFPR). Programa de Pós Graduação em Desenvolvimento Regional (PPGDR) Campus Pato Branco/PR.

E-mail: marciogazolla1@gmail.com

\section{Arlindo Jesus Prestes de Lima}

Doutor em Planejamento e Desenvolvimento Rural Sustentável. Professor da Universidade Federal de Santa Maria (UFSM) - Campus de Frederico Westphalen/RS. Email: arlindojplima@gmail.com

\section{Carolina Brignoni}

Mestre em Desenvolvimento Rural. Bolsista de Extensão no País (EXP) do NEA.

E-mail: carolinabrignoni@yahoo.com.br

\section{Andressa Bammesberger}

Graduanda em Engenharia Sanitária e Ambiental da Universidade Federal de Santa Maria (UFSM). Bolsista de Iniciação ao Extensionismo (IEX) do NEA.

E-mail: abammesberger@hotmail.com 